\title{
Evaluation of Antidepressant Activity of Dolichos Biflorus Methanolic Seed Extract in Animal Models of Depression
}

\author{
Mahalaxmi S Petimani ${ }^{1}$, Prabhakar Adake ${ }^{2, *}$, Abhilash Aditya ${ }^{3}$ \\ ${ }^{1}$ Assistant Professor of Biochemistry, Yenepoya Medical College, Mangalore-575018, India \\ ${ }^{2}$ Associate Professor of Pharmacology, Yenepoya Medical College, Mangalore-575018, India \\ ${ }^{3}$ Final Year Medical Scholar, Yenepoya Medical College, Mangalore-575018, India \\ ${ }^{*}$ Corresponding Author: dradake82@gmail.com
}

Copyright $\bigcirc 2019$ by authors, all rights reserved. Authors agree that this article remains permanently open access under the terms of the Creative Commons Attribution License 4.0 International License

\begin{abstract}
Objective: To evaluate the antidepressant activity of methanolic extract of Dolichos Biflorus seeds in Swiss albino mice. Methodology: A total of $72(n=72)$ Swiss albino male mice were used in the study. They were divided into 12 groups of six mice in each. First six groups were evaluated by Tail Suspension Test (TST) and remaining by Forced Swim Test (FST). First group of mice (control) received normal saline $10 \mathrm{mg} / \mathrm{kg}$, second group (standard) received Imipramine $10 \mathrm{mg} / \mathrm{kg}$ and third, fourth, fifth and sixth groups (test) respectively received methanolic extract of Dolichos Biflorus seeds (MEDB) $100 \mathrm{mg} / \mathrm{kg}, 200 \mathrm{mg} / \mathrm{kg}, 300 \mathrm{mg} / \mathrm{kg}$ and $400 \mathrm{mg} / \mathrm{kg}$ dose orally for 30 days. They were evaluated for antidepressant activity using TST after 60 minutes of drug administration on $30^{\text {th }}$ day. Duration of immobility was noted for six minutes for each mouse in all groups. Similarly, remaining six groups $\left(7^{\text {th }}\right.$ to $\left.12^{\text {th }}\right)$ received the same drugs and evaluated for antidepressant activity using FST after 60 minutes of drug administration. Results: Results were analyzed by Kruskal-Wallis non-parametric test followed by Dunnet's test for comparison between groups. The immobility periods were expressed in mean $\pm \mathrm{SD}$. The

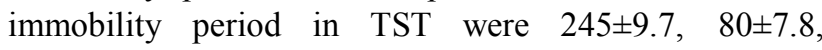
$216.4 \pm 4.9,225.3 \pm 2.3,198.4 \pm 3.2$ and $185.4 \pm 2.7$ seconds respectively for control, standard and four test groups $(100 / 200 / 300 / 400 \mathrm{mg} / \mathrm{kg})$. Similarly, immobility periods of $139.33 \pm 7.9,71.66 \pm 4.9,54.7 \pm 2.9,58 \pm 5.2,126.2 \pm 7.9$ and $113.4 \pm 2.8$ seconds were noted for FST for remaining six groups of mice. In TST, test drug MEDB in all the doses $(50 / 100 / 200 / 300 / 400 \mathrm{mg} /$ day $)$ failed to show statistically significant antidepressant action when compared to control group ( $>0.05$ ). Whereas, in FST, MEDB in a dose of $200 \mathrm{mg} / \mathrm{kg}$ has shown statistically significant $(\mathrm{p}<0.05)$ antidepressant action when compared to control. Conclusion: Present study shown methanolic extract of Dolichos Biflorus seeds (MEDB) has significant
\end{abstract}

antidepressant activity at the dose of $200 \mathrm{mg} / \mathrm{kg}$ in FST model of depression in mice.

Keywords Methanolic Extract of Dolichos Biflorus Seeds (MEDB), Forced Swim Test, Tail Suspension Test

\section{Introduction}

Major depressive disorder (MDD) is a mental disorder common in psychiatry wherein patient presents with one of two major symptoms, constant sadness or anhedonia, accompanied by secondary symptoms like feelings of worthlessness, difficulty concentrating, changes in diet, and sleep patterns, for at least period of two weeks.[1] It is a relapsing, remitting illness having greater than $40 \%$ rate of recurrence over a period of two years. [2] It must be distinguished from normal grief, sadness, disappointment, and dysphoria or demoralization associated with medical illness and from bipolar disorder in which depression alters with hypomania or mania. The condition is often undiagnosed and frequently undertreated.[3]

Depression often co-exists with other illnesses like anxiety disorders, including panic-agoraphobia syndrome, generalized anxiety disorder, posttraumatic stress disorder, and obsessive-compulsive disorder. Alcohol and other substance abuse or dependence may also present with depression.

Depression results from a combination of multiple etiologic factors-genetic, biochemical, psychodynamic, and socio-environmental. The children of a depressed person are at a higher risk for depression. Monozygotic twins have a higher concordance rate $(46 \%)$ than dizygotic siblings (20\%). [4] Biochemical factors include decrease in the levels of neurotransmitters like nor-epinephrine and serotonin in the brain. Crucial life events, particularly the 
death or loss of a loved one or an emotional trauma can precede the onset of depression.

Various drugs are available for the treatment of depression. They include monoamine oxidase inhibitors, selective and non-selective monoamine reuptake inhibitors and selective serotonin reuptake inhibitors. These medications work by normalizing the levels of neurotransmitters, notably serotonin and nor-epinephrine. Approximately 60 to $70 \%$ of depressed patients respond to conventional antidepressants, if it is given in a sufficient dose for 6-8 weeks. But there is no ideal antidepressant; with rapid onset of action, moderate half-life, a low side-effect profile, minimal interaction with other drugs, and safety in overdose.[5] More over conventional antidepressant drugs have unusual side effects. The need for newer, better-tolerated and more efficacious treatments remains high.

Recently, increased pro-inflammatory cytokines (IL-6, TNF- $\alpha, \quad$ NF- $\kappa \mathrm{B}), \quad$ increased Nitric Oxide (L-arginine-NO-cGMP pathway), and increased oxidative stress are implicated in the pathogenesis of depression.[6-8] Moreover, individuals with depression display lower serum antioxidant potentials, coenzyme Q10 (CoQ10), and reduced brain GSH levels as compared to matched controls.[9-12] Moreover, there is increased generation of free radicals $\left(\mathrm{H}_{2} \mathrm{O}_{2}, \mathrm{O}^{2} \cdot\right)$ in MDD individuals due to increased serum Xanthene Oxidase (XO) levels.[13,14] A recent post mortem study found increased XO activity in the thalamus and putamen of patients with recurrent MDD.[15]

It was observed that pretreatment with amitriptyline and fluoxetine associated with increased Super Oxide Dismutase activity, and no signs of cell death were observed in cultured pheochromocytoma cells suggesting neuroprotective property.[16] In another study, imipramine, fluvoxamine, or reboxetine inhibited NO production in a dose-dependent manner in an activated microglia cell culture protocol. [17] This has shown that these antidepressant drugs have additional anti-oxidant property. Dolichos Biflorus being an ancient ayurvedic drug with anti-oxidant action, the present study was undertaken to evaluate its antidepressant action in albino mice.

\section{Materials and Methods}

Institutional Ethical clearance was obtained before conducting the study. Male Swiss albino mice weighing 25-35 g. were used for the study. The mice were inbred in the central animal house of the Department of Pharmacology, Yenepoya Medical College, Yenepoya University, Mangalore, under suitable conditions of housing, temperature, ventilation and nutrition. The study was conducted in accordance with standard CPCSEA guidelines.

\subsection{Drugs}

- Dolichos Biflorus seeds were purchased from local stores of Mangalore, India. The seeds were authenticated by Professor of Botany Department, Mangala Gangotri University, Mangalore. Dried seeds were grinded using mixer-grinder having 550 watts, $17000 \mathrm{rpm}$ rotating speed electrical motor. The seeds were grinded and crushed well and uniformly for 10 minutes with highest precaution to avoid any contamination and made them as particle-sized powder $(<0.5 \mathrm{~mm})$. The powdered material was packed in plastic pouches and stored in normal room temperature until use. Seed powder was subjected to solvent extraction with methanol in a soxhlet apparatus. After exhaustive extraction, the methanolic extract of Dolichos Biflorus (MEDB) was dried at low temperature under reduced pressure in a rotary evaporator to obtain brownish-black colored residue which was used for antidepressnat studies.

- Pure form of imipramine was obtained from Torrent Pharmaceutical Company, Ahmadabad, India.

- $\quad 0.9 \%$ normal saline was obtained from Yenepoya Pharmacy, Yenepoya Medical College Hospital, Yenepoya University, Mangalore

\subsection{Acute Oral Toxicity Test}

Acute oral toxicity was done in male Swiss albino mice according to Organization of Economic Co-operation and Development (OECD) guidelines, ANNEX-423. [18] Animals were administered methanolic extract of Dolichos Biflorus seeds in a dose of 50,100, 200 and $2000 \mathrm{mg} / \mathrm{kg}$ per orally to find out safe dose range in animals. Animals were observed for 48 hours from the time of drug administration. Mice were looked for general behavior and mortality.

\subsection{Inclusion Criteria}

- Male Swiss albino mice weighing between 25-35g.

- $\quad$ Age 3-4 months.

- Healthy with normal behavior and activity.

\subsection{Exclusion Criteria}

- $\quad$ Mice $<25 \mathrm{~g}$ and $>35 \mathrm{~g}$ and age $<3$ months and $>4$ months.

- Female mice will be excluded

- Animals previously used in other experiments.

A total of 72 animals $(n=72)$ were used. They were divided into 12 groups of 6 animals each.

Animals were evaluated for antidepressant activity using two models - Tail suspension test (TST) and Forced swimming test (FST). The experiment was conducted in Post Graduate Experimental Laboratory of the Department of Pharmacology, Yenepoya Medical College, Yenepoya 
University, between 8:00 A.M. to 2:00 P.M. The food and water was removed during study period. Animals were weighed and appropriate dose of drug was given per oral to the different groups for 30 days. The experiment was conducted sixty minutes after the oral administration of the drug. Sufficient gap was maintained for giving the drug so that all the animals were tested after $30 \mathrm{~min}$ of drug administration.

\subsection{Tail Suspension Test (TST)}

Steru et al. developed the Tail Suspension Test to evaluate antidepressant activity. [19] The model used in the present experiment was similar to the original method described. Animals were suspended upside down on a metal rod at a height of $55 \mathrm{~cm}$ from the ground level with the help of an adhesive tape placed approximately $1 \mathrm{~cm}$ from the tip of the tail. Initially the animals tried to escape by making vigorous movements but when unable to escape became immobile. The animal was considered immobile when it did not show any movement of body and hanged passively. The immobility displayed by rodents when subjected to this kind of unavoidable and inescapable stress has been hypothesized to reflect behavioral despair which in turn may reflect depressive disorders in humans. The total duration of immobility was noted during six minutes period. Each animal was used only once.

The animals for Tail Suspension Test were divided as follows.

- Group I: Received $10 \mathrm{ml} / \mathrm{kg}$ of normal saline p.o

- Group II: Received $10 \mathrm{mg} / \mathrm{kg}$ Imipramine p.o

- Group III: Received methanolic extract of Dolichos Biflorus (MEDB) $100 \mathrm{mg} / \mathrm{kg}$ p.o

- $\quad$ Group IV: Received methanolic extract of Dolichos Biflorus (MEDB) $200 \mathrm{mg} / \mathrm{kg}$ p.o

- $\quad$ Group V: Received methanolic extract of Dolichos Biflorus (MEDB) $300 \mathrm{mg} / \mathrm{kg}$ p.o

- Group VI: Received methanolic extract of Dolichos Biflorus (MEDB) $400 \mathrm{mg} / \mathrm{kg}$ p.o

\subsection{Forced Swim Test (FST)}

Porsolt et al. developed the Forced Swimming model to evaluate antidepressant activity. [20] The model used in the present experiment is similar to the original method described. The animals were forced to swim in a plastic cylinder measuring $30 \times 30 \mathrm{~cm}$ containing water to a depth of $20 \mathrm{~cm}$ at room temperature. After an initial two minutes of vigorous activity, each animal assumed a typical immobile posture. The mouse was considered immobile when it remained floating in the water without struggling, making only minimum movements of its limbs necessary to keep its head just above the water level. Total duration of immobility was recorded during next 4 minutes of total 6 minutes duration. The differences in the immobility period were noted after administering drugs in all the group of animals. Each animal was used only once.

Animals for Forced Swimming Test (FST) were divided as follows,

- Group VII: Received $10 \mathrm{ml} / \mathrm{kg}$ of normal saline p.o

- Group VIII: Received 10 mg/kg Imipramine p.o

- Group IX: Received methanolic extract of Dolichos Biflorus (MEDB) $100 \mathrm{mg} / \mathrm{kg}$ p.o

- Group X: Received methanolic extract of Dolichos Biflorus (MEDB) 200mg $/ \mathrm{kg}$ p.o

- Group XI: Received methanolic extract of Dolichos Biflorus (MEDB) $300 \mathrm{mg} / \mathrm{kg}$ p.o

- $\quad$ Group XII: Received methanolic extract of Dolichos Biflorus (MEDB) 400mg/kg p.o

\subsection{Statistical Analysis}

Statistical analysis was done by Kruskal-Wallis non-parametric test followed by Dunnet's test for comparison between groups.

\section{Results}

In this study, effort was made to evaluate antidepressant activity of methanolic extract of Dolichos Biflorus (MEDB) in albino mice using tail suspension test (TST) and forced swim test (FST). Mice were divided into 12 groups and dosed with normal saline (control), Imipramine (standard) and MEDB (test-50,100,200,300, 400) for 30 days. The antidepressant activity was assessed on $31^{\text {st }}$ day. The immobility time in TST and FST was recorded for each mouse. Surprisingly, the MEDB has failed to show statistically significant $(p>0.05)$ antidepressant activity in TST for all the doses when compared to control and standard groups. However, in forced swim model, MEDB in a dose of $200 \mathrm{mg} / \mathrm{kg}$ has shown statistically significant antidepressant action when compared to control group.

Table 1. The effect of Methanolic extract of Dolichus Biflorus (MEDB) on immobility period in Tail Suspension Test

\begin{tabular}{|c|c|c|c|c|}
\hline Group No & Drug/Treatment & No of animals & Dose $\left(\mathrm{Kg}^{-1}\right)$ & $\begin{array}{c}\text { Immobility Time in sec } \\
(\text { Mean } \pm \text { SD })\end{array}$ \\
\hline 01 & Control (NS) & 6 & $10 \mathrm{ml}$ & $245 \pm 9.7$ \\
\hline 02 & Standard (Imipramine) & 6 & $10 \mathrm{mg}$ & $80.66 \pm 7.8^{* *}$ \\
\hline 03 & MEDB & 6 & $100 \mathrm{mg}$ & $216.4 \pm 4.9$ \\
\hline 04 & MEDB & 6 & $200 \mathrm{mg}$ & $225.3 \pm 2.3$ \\
\hline 05 & MEDB & 6 & $300 \mathrm{mg}$ & $198.4 \pm 3.2$ \\
\hline 06 & MEDB & 6 & $400 \mathrm{mg}$ & $185.4 \pm 2.7$ \\
\hline
\end{tabular}


$\mathrm{n}=6$, Observations are Mean \pm SD. Kruskal-Wallis test followed by Dunnet's Multiple comparison test. ${ }^{*} \mathrm{p}<0.05,{ }^{* *} \mathrm{p}<0.001$.

MEDB: Methanolic Extract of Dolichus Biflorus seeds

Table 2. The effect of Methanolic extract of Dolichus Biflorus (MEDB) on immobility period in Forced Swim Test

\begin{tabular}{|c|c|c|c|c|}
\hline Group No & Drug/Treatment & No of animals & Dose (Kg $\left.{ }^{-1}\right)$ & Immobility Time in sec (Mean \pm SD) \\
\hline 01 & Control(NS) & 6 & $10 \mathrm{ml}$ & $139.33 \pm 7.9$ \\
\hline 02 & Standard (Imipramine) & 6 & $10 \mathrm{mg}$ & $71.66 \pm 4.9^{*}$ \\
\hline 03 & MEDB & 6 & $100 \mathrm{mg}$ & $54.7 \pm 2.9$ \\
\hline 04 & MEDB & 6 & $200 \mathrm{mg}$ & $58 \pm 5.2 *$ \\
\hline 05 & MEDB & 6 & $300 \mathrm{mg}$ & $126.2 \pm 7.9$ \\
\hline 06 & MEDB & 6 & $400 \mathrm{mg}$ & $113.2 \pm 2.8$ \\
\hline
\end{tabular}

$\mathrm{n}=6$, Observations are Mean \pm SD. Kruskal-Wallis test followed by Dunnet's Multiple comparison test. ${ }^{*} \mathrm{p}<0.05,{ }^{* *} \mathrm{p}<0.001$.

MEDB: Methanolic Extract of Dolichus Biflorus seeds

\section{Discussion}

Herbal medicines have great contribution towards health care. More number of drugs which are synthesized from plants are being approved for the management of diseases. Dolichos Biflorus is not only edible beans but also has medicinal properties. It has been used for the treatment of piles, pain, constipation, wounds, urinary calculi, cough, edema, asthma, etc. The seeds of Dolichos Biflorus also have antilithiatic, antihepatotoxic and hypolipidemic activity.

Chemical constituents like streptogenin, $\beta$-sitosterol, bulbiformin, linoleic acid, polyphenols, oxalates and crude fibers have been identified in Dolichos Biflorus plant. A number of isoflavones have been isolated from the leaves and stems namely genistein, dalbergioidin, kievitone, phaseollidin and isoferrerin. [21] The seeds of Dolichos Biflorus contain 5-hydroxy-7, 3, 4-trimethoxy-8methylisoflavone-5-neohesperidoside, genistein, $\beta$-sitosterol and 5-o- $\alpha$ L-rhamnopyranosyl (1-2)- $\beta$-D-glucopyranoside. Two Ayurvedic preparations, having Dolichos Biflorus as an ingredient, have shown their antioxidant and free radical scavenging activity. [22]

Study by Muthu AK et al. has shown that methanol extract of Dolichos Biflorus Linn. has potent antioxidant action in high fat diet fed rabbits. [23] Previous studies by Batoo et al. have concluded that aqueous extract of Dolichos biflorus seeds has diuretic activity, helpful in nephrolithiasis. [24] It was also found that Dolichos Biflorus has anti-diabetic and hypolipidemic activity in experimental animals. [25] In the view of effectiveness of Dolichos Biflorus herb on various disease ailments, effort was made in the present study to assess the antidepressant action of methanolic seed extract of Dolichos Biflorus in experimental models. The results of our study have concluded that MEDB in a dose of $200 \mathrm{mg} / \mathrm{kg}$ has shown statistically significant antidepressant action when compared to control group. The possible mechanism of antidepressant activity could be antioxidant action of Dolichos Biflorus. However, further research needs to be conducted to elucidate detailed pharmacokinetic and pharmacodynamic properties of Dolichos Biflorus.

\section{Conclusions}

Present study has shown methanolic extract of Dolichos Biflorus seeds (MEDB) has significant antidepressant activity at the dose of $200 \mathrm{mg} / \mathrm{kg}$ in FST model of depression in mice.

\section{Acknowledgements}

Authors are thankful to Indian Council of Medical Research (ICMR) for granting this project under STS scheme.

\section{REFERENCES}

[1] Diagnostic and Statistical Manual of Mental Disorders. 4th ed, Text Revision ed. Washington, DC American Psychiatric Association; 2000.

[2] Solomon DA, Keller MB, Leon AC, Mueller TI, Lavori PW, Shea MT, et al. Multiple recurrences of major depressive disorder. Am J Psychiatry. 2000; 157(2):229-33.

[3] Suominen KH, Isometsa ET, Henriksson MM, Ostamo AI, Lonnqvist JK. Inadequate treatment for major depression both before and after attempted suicide. Am J Psychiatry. 1998; 155(12):1778-80.

[4] Sullivan PF, Neale MC, Kendler KS. Genetic epidemiology of major depression: review and meta-analysis. Am J Psychiatry 2000 Oct; 157(10):1552-62.

[5] Victor I. Reus, MD. Mental disorders. In: Fauci, MD, Eugene Braunwald, Kasper, MD, editors. Harrison's Principles of Internal Medicine. $17^{\text {th }}$ ed. New York: McGraw-Hill Medical Publishing Division; 2008. Pp.1720-24.

[6] JT Coyle, P Puttfarcken. "Oxidative stress, glutamate, and neurodegenerative disorders" Science 1993; 262:689-695.

[7] A Gardner and RG Boles. "Beyond the serotonin hypothesis: mitochondria, inflammation and neurodegeneration in major depression and affective spectrum disorders," Progress in 
Neuro-Psychopharmacology and Biological Psychiatry 2011; 35(3): 730-743.

[8] K Chopra, B Kumar, A Kuhad, "Pathobiological targets of depression". Expert Opinion on Therapeutic Targets 2011; 15(4):379-400.

[9] A. Sarandol, E. Sarandol, S. S. Eker, S. Erdinc, E. Vatansever, and S. Kirli, "Major depressive disorder is accompanied with oxidative stress: short-term antidepressant treatment does not alter oxidative - antioxid ative systems," Human Psychopharmacology 2007; 22(2): $67-73$.

[10] BE Cumurcu, H. Ozyurt, I. Etikan, S. Demir, and R. Karlidag, "Total antioxidant capacity and total oxidant status in patients with major depression: impact of antidepressant treatment," Psychiatry and Clinical Neurosciences 2009; 63(5): 639-645.

[11] P. Gałecki, J. Szemraj, M. Bienkiewicz, A. Florkowski, and E. Gałecka, "Lipid peroxidation and antioxidant protection in patients during acute depressive episodes and in remission after fluoxetine treatment," Pharmacological Reports 2009; 61(3): 436-447.

[12] J. W. Gawryluk, J. F. Wang, A. C. Andreazza, L. Shao, and L. T. Young, "Decreased levels of glutathione, the major brain antioxidant, in post-mortem prefrontal cortex from patients with psychiatric disorders," International Journal of Neuropsychopharmacology 2011;14(1):123-130.

[13] M. Maes, I. Mihaylova, M. Kubera, M. Uytterhoeven, N. Vrydags, and E. Bosmans, "Lower plasma Coenzyme Q10 in depression: a marker for treatment resistance and chronic fatigue in depression and a risk factor to cardiovascular disorder in that illness," Neuroendocrinology Letters 2009; 30(4): 462-469.

[14] R Harrison. "Physiological roles of xanthine oxidoreductase". Drug Metabolism Reviews, 2004; 36(2): 363-375.

[15] TM Michel, S Camara, T Tatschner. "Increased xanthine oxidase in the thalamus and putamen in depression," World Journal of Biological Psychiatry 2010; 11(2): 314-320.

[16] N Kolla, Z Wei, JS Richardson, XM Li. "Amitriptyline and fluoxetine protect PC12 cells from cell death induced by hydrogen peroxide." Journal of Psychiatry and Neuroscience 2005; 30(3): 196-201.

[17] S Hashioka, A Klegeris, A. Monji. "Antidepressants inhibit interferon- $\gamma$-induced microglial production of IL-6 and nitric oxide," Experimental Neurology 2007; 206(1): 33-42.

[18] Adake P, Petimani MS, Jayaraj M, Rao SN. Preclinical evaluation of Boswellia serrata for anxiolytic activity. Int $J$ Basic Clin Pharmacol. 2015; 4(3): 551-555.

[19] Steru L, Chermat R, Thierry B, Simon P. The tail suspension test: a new method for screening antidepressants in mice. Psychopharmacology (Berl). 1985; 85(3): 367-70.

[20] Blier P, De Montigny C. Current advances and trends in the treatment of depression. Trends Pharmacol. Sci. 1994; 15: 230-236.

[21] Keen NT, Ingham JL, Naturforsch ZC. Phytoalexins from Dolichos bijlorus, Biosci. 1980; 35C: 923-926.
[22] Limi Elizabeth Math ew, G. Sindhu, A. Helen. Dolichos Biflorus exhibits anti-inflammatory and antioxidant properties in an acute inflammatory model. Journal of food and drug analysis 2014; 22: 455-462.

[23] Muthu A K, Sethupathy S, Manavalan R, Karar PK. Antioxidant potential of methanolic extract of Dolichos Biflorus Linn in high fat diet fed rabbits. Indian J Pharmacol 2006; 38:131-2.

[24] Batoo, Azhar Shuaib, Dey Sahadeb, Bhat, Manzoor Ahmad and Dan, Ananya. Evaluation of diuretic effect of aqueous extract of 'Dolichos Biflorus' seeds against ethylene glycol induced renal stone in experimental rats. Journal of Animal Research 2015; 5(4): 773-777.

[25] Parthsarthi, Brijesh Purwar, Yogesh Saxena. Effect of Dolichos Biflorus on blood sugar and lipids in diabetic rats. Indian J Physiol Pharmacol 2013; 57 (1):63-71. 